\title{
Preschool Children's Understanding of Numbers from the Multiple Representation Perspective
}

\author{
Ayminsyadora Ayub ${ }^{1}$, Munirah Ghazali ${ }^{1}$, Abdul Razak Othman ${ }^{2}$ \\ ${ }^{I}$ School of Educational Studies, Universiti Sains Malaysia, Malaysia \\ ${ }^{2}$ Institut Pendidikan Guru Kampus Tuanku Bainun, Malaysia
}

\begin{abstract}
Many research on primary school children in Malaysia indicate an over reliance on the written symbols representation (Munirah, 2001; Parmjit, 2005; Munirah\& Noor Azlan, 2002; Chinappan \& Ambigapathy, 2009; Mohini \& Jacinta, 2010). This is a cause for concern as researchers draw strong connections between the representations children use and their understanding (Lamon, 2001). Janvier (1987) describes understanding as a "cumulative process mainly based upon the capacity of dealing with an 'everenriching' set of representations". Furthermore, representations are considered as a means in the formation of conceptual understanding. The ability to move smoothly between various representations of the same concept is seen as an indication of conceptual understanding and also as a goal for instruction (Lesh, Behrand Post, 1987). Moreover, according to Kaput (1991), possessing an abstract mathematical concept is better regarded as a notationally rich web of representations and applications. This paper reports on a research that was carried out to investigate preschool children's mapping of the number words onto it's symbolic and concrete representation. A total of thirty 5 and 6 year old preschool children were individually interviewed on number name and it's symbolic and concrete representation. Findings suggest that there are children who are able to move smoothly between the various number representations. Pedagogical implications from the findings will be discussed.
\end{abstract}

Keywords:_Childhood,Mathematics,Representations

\section{INTRODUCTION}

Representations play an important and necessary role in the teaching and learning of mathematics. "The ways in which mathematical ideas are represented is fundamental to how people can understand and use those ideas" (NCTM, 2000). Representations have become one of the major aspects in the teaching and learning of mathematics as emphasized by many theorists. The concept of using representations as a means of communicating abstract mathematical ideas is a prominent focus of research in teacher knowledge and student learning (Borko \& Putnam, 1996). Seeger, Voight, \& Werschescio (1998) summarized some definitions of representations which include "any kind of mental state with a specific content; a mental reproduction of a former mental state; a picture, symbol, or sign; symbolic tool one has to learn their language; a something "in place of "something else". The National Council of Teachers of Mathematics (NCTM) (2000) considers representation as both a process and a product.

Researchers have categorized the representations into two categories of representations; internal and external. Representations are conceptualized slightly different, however its refer to either internal, external or both. For example, to constructivists, internal representations happen inside the students' heads, and external representations are situated in the students' environments (Cobb, Yackel, and Wood, 1992; Goldin \& Shteingold, 2001). Pape and Tchoshanov (2001) considered internal representations as mathematical ideas developed by the learner through experience, whereas external representations come in the form of symbols, equations, pictures, charts and graphs According to Goldin \& Janvier (1998, p. 3), internal representations are defined as "individual cognitive configurations inferred from human behavior describing some aspects of the process of mathematical thinking and problem solving"; on the other hand, external representations can be described as "structured physical situations that can be seen as embodying mathematical ideas (pp.3)" Goldin (1998a) connected any physical situation including mathematical objects to external representations. For instance; a number line, illustrated relationships among numbers or a computer-based environment in which mathematical construct can be manipulated as external representations. Internal representations, on the other hand, to the learner only. This means that what students conceptualize in their minds can be labeled as internal representation (Goldin, 1998a). 


\section{RELATED THEORIES OF REPRESENTATIONS}

In their earlier works, Dienes (1960) and Bruner (1966) highlighted the component of representation in the specific stage of their theory. For Dienes (1960) students move through five levels to create a thorough mathematical understanding. The levels are: free play (students work with physical materials and manipulatives to discover basics about the concept), generalization (the student notices patterns and commonalities), representation (students represent the images), symbolization (the student describes their representation using mathematic language and symbols) and formalization (students create a set of rules and algorithms to match with their understanding of the concept). By using less number of stages, Bruner (1966) proposed that students need three levels of engagement to fully build a complete understanding of a mathematics concept. The levels are as follows: enactive (students use manipulatives and other concrete materials to construct their understanding), iconic (students represent their understanding using pictures and graphs) and the final level is symbolic (the students use numerals to represent what they know).

About three decade later Pirie \& Kieren, (1994b) introduced a theory related to how student's mathematical understanding grows and develops concerning a specific mathematical concept or topic. Representation is also included in the theory. Pirie-Kieren theory provides eight potential levels of student understanding based on the cognitive changes that occur during the processes of learning mathematics. The consecutive layers are described below.

(a) Primitive Knowing refers to the knowledge that an individual brings to a setting or previous knowledge.

(b) Image Making refers to the level where the student can use Primitive Knowing in new ways that involve actions and activities with that knowledge.

(c) Image Having layer shows a student ability to use a mental construct of a concept without the need for the activities that contributed his or her Image Making.

(d) Property Noticing happens when a student construct contextually relevant properties that are related to his or her Image Having by connecting, manipulating or combining aspects of those images

(e) Formalizing At this level student is abstracting the formal mathematical characteristic or properties of the images, forming a concept and then enunciating a formal definition or algorithm

(f) Observing requires a student to reflect on and use his or her formal understanding as theorems and can make predictions without the need for actions.

(g) Structuring refers to the student ability to justify mathematical arguments through logic and proof without the need for physical or algorithmic actions by considering formal observations as theory and taking the inter-connections between theorems into account.

(h) Inventising is the highest level, where a student does not depend on the ideas and images that contributed to the understanding. The student displays a strong understanding and now able to create new mathematical questions that can potentially lead to a new concept.

In the Pirie-Kieren theory, the levels of Image Making, Image Having and Property noticing are closely related to representations. In summary, all theories deal with internal and external representations.

\section{The Concept Of Multiple Representations}

Moving from external and internal representations, the concept of multiple representations takes into account various representations and the interconnectedness between them. Owens and Clements (1998) characterized the theory of multiple representations as follows: "(a) identifying a mathematical idea in a set of different representations, (b) manipulating the idea within a variety of representations, (c) translating the idea from one representation to another, (d) constructing connections between internal representations in one's network of representations, (e) being able to decide the appropriate representation to use in a given problem, and (f) identifying the strengths and weaknesses, differences and similarities of various representation of a concept (p.203)". By using multiple representations, students can deepen their mathematics understanding, especially if they can easily transfer from one representation form to another representation form (Suh \& Moyer, 2007). If a student is only capable of using one form, it means that the student has only made a limited number of connections associated to that type of form or even worse, they may have memorized the procedure of how to use the form but not truly understand the concept that the form represents. Using multiple representations should get the student to think about how the concept relates to the real world, justify their thought processes and clarify their thinking (Pape \& Tchoshanov, 2001). The representation form should be used to strengthen the connections that they have made in the construction of knowledge.

The theory of multiple representations which is called Lesh Multiple Representations Translations Model (LMRTM) has been proposed by Richard Lesh (1979). Lesh, Post and Behr (1987b) viewed both internal and external representations as crucial elements for understanding mathematical concepts and both are interrelated. since "external (and therefore observable) embodiments of students' internal conceptualizations" (Lesh,

www.iosrjournals.org
"Acknowledgement to USM Research University Grant (1001/PGURU/816166)"

94 | Page 
et al.1987b, p. 34). This model argues that the ability of making translations between and within modes of representations would reflect the student's understanding of a concepts. He described five distinct modes of representations (see Figure 1) that occur in mathematics learning and problem solving; they are "(1) real-world situations -in which

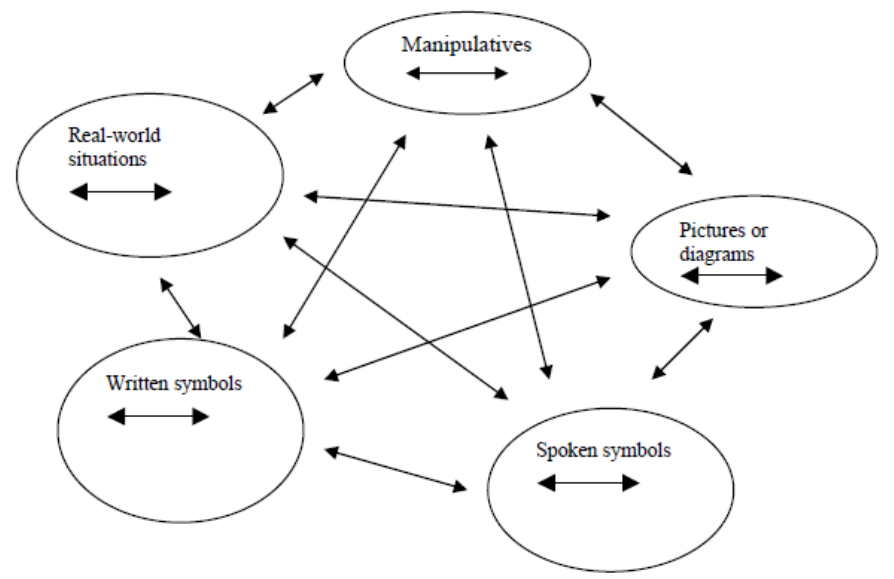

Fig.1: Lesh Multiple Representations Model (LMRTM)

knowledge is organized around "real world" events; (2) manipulatives -in which the "elements" in the system have little meaning but the "built in" relationships and operations fit many everyday situations; (3) pictures or diagrams -static figural models; (4) spoken symbols -it can be everyday language; (5) written symbols -in which specialized sentences and phrases take place" (Lesh, et al. 1987b, p. 38).

\section{Review Of Related Research}

Research on representations has been conducted across all levels of years ranging from preschool up to higher education level. This paper reviews the related research with respect to preschool ages. Thomas, Mulligan, and Goldin (2002) conducted a research on children's internal representations. The study involved children's drawings and explanations of the numbers from 1 to 100 . By using 172 children from the grades $\mathrm{K}$ to 6 as samples, the study aimed to infer children's internal representations from their external representations. During the interviews, the children were asked to describe their understandings of numeration. They provided 89 different tasks in five categories: counting, grouping, place value, structure of numeration, and visualization. The visual task was first assigned, in order not to let children to be influenced the external representations before they create their internal representations. A total of 264 interview scripts, together with the external pictorial and notational representations were collected from this sample. Based on the findings, the researchers concluded that the children cognitive representations of numeration can be developed over time. From the children's ability to deal with external representations, the findings showed that the children used a variety of representations of the numerals 1-100 than the researchers expected. Another interesting finding was that their representations were highly unconventional. The children also tend to code formal number representations in a shape of spiral, or flashing cards. The researchers concluded that their external representations would be more coherent and wellorganised, and so as to their numerical understandings provided children have more developed internal representations.

In another study, Ainsworth and van Labeke (2002) studied the factors that have effects on the translations among representations of learners. This experimental study involved three experiments including four groups of children who were five-year-old. The first group received pictorial representations, the second group received only mathematical representations, the third group received mixed representations including pictorial and mathematical representations, and the fourth group had no intervention as a control group. The study used the specific software called CENTS to provide a computer-based environment. In using the CENTS, students are required to deal with external mathematical representations in order to improve their computational skills with numbers. To measure the children achievement, an instrument called "Think and Solve Mental Math" was administered in a pre and post test. The findings of this study showed that, children were able to translate from pictorial representation to the mathematical representation. However, they failed to make translations in reverse. Furthermore, even children who did well on translations between pictorial and mathematical did not get the highest score on post test. The study noticed that the children who preferred mostly the mathematical representations got significantly higher scores on post test administration. These findings led researchers to the notion that dealing with different representations and being able to make translations among them might not be a guarantee a good performance on mathematics tests. The researchers hypothesized that if two external 
representations support the same concept, the translations between those external representations are easy and beneficial for mathematics learning, whereas if the external representations are dissimilar, the students have difficulty in making translation between them.

\section{Problem Statement}

Theoretically, multiple representations demand the understanding of a mathematical concepts in the form of different representations. The ability to move from one representation to another (Lesh, Post and Behr, 1987) provides an indicator of how much learning of a mathematical concept take place. In addition, learning also depends on the maturity of the children. As described by Piaget (1972), preschool children of ages between two and six-years-old are belong to the preoperational stage. At this stage, the children develop their language, become increasingly adept at using symbols and able to practice role play. On the other hand, children do not yet understand concrete logic, cannot mentally manipulate information, and are unable to take the point of view of other people. However, the use of multiple representations among children of preoperational stage requires further explanation with respect to their ability.

\section{Research Objective}

The objective of the study was to describe the ability in using different representations among preschool children.

\section{Research Questions}

The study was carried out to address the following question; To what extent do preschool children use multiple representations in learning numbers (1 to 10)?

\section{Method}

\subsection{Participants}

Thirty children were selected from a kindergarten in Penang, a state in Malaysia, as participants. We grouped them into two groups: 15 children of five-year-old and 15 children of sixyear-old.

\subsection{Procedure}

The children were interviewed individually and were tested on four different tasks. For the first task, Arabic digits from 1 to 10, was randomly presented on separate cardboards and the children were asked to say the number name aloud without receiving feedback. The score of 1 point for each correct item was given. In the second task, they were asked to count one to ten using their fingers. The correct and wrong responses were recorded. Next, for the third tasks they were asked to count a set of marbles based on numbers given by the researcher. Sets of marbles are categorized into two categories; small quantity (comprised 2, 3 or 4 marbles) and big quantity (comprised 8, 9 or 10 marbles). Lastly, in task 4 , they were tested on a dot numeration task. The children were then had to name aloud the quantity of the dots that were displayed by the researcher. The children were allowed to use any strategy before enumerate the dots.

Prior to actual data gathering, a pilot study was conducted. The purpose of the pilot study was to ensure the children understand the direction given by the researcher. The researcher asked them informally related to the tasks to be given. We found that the children were able to understand the direction and tried to response to the questions. The finding from the pilot study led us to improve the method to give direction and add additional questions to produce reliable data.

\section{Results Of The Study}

The results of the study are reported according to tasks as follows;

\subsection{Task 1: Say the number names}

\begin{tabular}{|c|c|c|c|c|}
\hline \multirow{3}{*}{ Number Shown } & \multicolumn{4}{|c|}{ Correct response } \\
\hline & \multicolumn{2}{|c|}{5 years old } & \multicolumn{2}{|c|}{6 years old } \\
\hline & $n$ & $\%$ & $n$ & $\%$ \\
\hline 1 & 14 & 93.3 & 15 & 100 \\
\hline 2 & 14 & 93.3 & 15 & 100 \\
\hline 3 & 14 & 93.3 & 15 & 100 \\
\hline
\end{tabular}




\begin{tabular}{ccccc}
4 & 12 & 80.0 & 15 & 100 \\
5 & 14 & 93.3 & 15 & 100 \\
6 & 13 & 86.7 & 15 & 100 \\
7 & 12 & 80.0 & 15 & 100 \\
8 & 9 & 64.3 & 15 & 100 \\
9 & 8 & 53.3 & 15 & 100 \\
10 & 12 & 80.0 & 15 & 100 \\
\hline
\end{tabular}

Table 1: Number and percentages of children's who responded correctly in saying number 1 to 10 .

Data of the first task in term of correct response with respect to age is shown in Table 1 above. The results show that all six-year-old children $(\mathrm{n}=15,100 \%)$ were able to say the number names $(1-10)$ correctly. However, the five-year-old children show different ability in saying number 1-10. A total of $14(93.3 \%)$ children were able to say number names (numbers $1,2,3,5$ ) correctly. The number of children answer correctly decreases when saying numbers $4,7,8$, and 10 . The number 9 becomes a great challenge to five-year-old children when almost half ( $\mathrm{n}=8,53.3 \%$ ) of them were able to say correctly. For number 8 , nine $(64.3 \%)$ children managed to answer correctly. For number 6 , a total of $13(86.7 \%)$ children answered correctly. There were $12(80 \%)$ children provided correct response to numbers $4,7,10$.

\subsection{Task 2: Using fingers to count numbers 1-10}

\begin{tabular}{|c|c|c|c|c|c|c|}
\hline \multirow[t]{2}{*}{ Age } & \multicolumn{2}{|c|}{$\begin{array}{l}\text { Say and count } \\
\text { correctly }\end{array}$} & \multicolumn{2}{|c|}{$\begin{array}{l}\text { Say correctly but } \\
\text { use fingers incorrectly }\end{array}$} & \multicolumn{2}{|c|}{ Unable to count } \\
\hline & $n$ & $\%$ & $n$ & $\%$ & $n$ & $\%$ \\
\hline 5 years & 12 & 80 & 2 & 13.3 & 1 & 6.7 \\
\hline 6 years & 15 & 100 & 0 & 0 & 0 & 0 \\
\hline
\end{tabular}

Table 2: Saying and counting responses (numbers 1-10) with respect to age

Table 2 shows that all six-year-old children $(\mathrm{n}=15,100 \%)$ were able to say the numbers $(1-10)$ and count with fingers correctly. However, not all five-year-old children $(\mathrm{n}=12,80 \%)$ managed to response correctly for both skills. There were two children (13.3\%) able to say correctly but use their fingers to count incorrectly. There was only one child who unable to say and count by using fingers correctly.

\subsection{Task 3: Counting a set of marbles based on numbers given}

\begin{tabular}{lccccc}
\hline & Age & \multicolumn{2}{c}{ Count correctly } & \multicolumn{2}{c}{ Unable to count } \\
\cline { 2 - 6 } & & $n$ & $\%$ & $n$ & $\%$ \\
\hline \multirow{2}{*}{ Small quantity } & 5 years & 13 & 86.7 & 2 & 13.3 \\
& 6 years & 15 & 100 & 0 & 0 \\
\hline \multirow{2}{*}{ Big quantity } & 5 years & 4 & 26.7 & 11 & 73.3 \\
& 6 years & 14 & 93.3 & 1 & 6.7 \\
\hline
\end{tabular}

Table 3: Number and percentages of children who count a set of marbles correctly

In Task 3 the children were asked to count the number of marbles in different sets of marbles. Again as shown in Table 3 below, all six-year-old children were able to count the small and big quantities correctly. Interestingly, a total of 13 children (86.7\%) of 5-year-old counted the marbles of small quantities correctly. However, only 4 of them (26.7\%) were able to count the marbles of big quantities correctly. Only one 6-years old child could not count correctly.

\subsection{Task 4: The strategies used to say the number that represents the dots}

In Task 4 , the children were encouraged to employ a strategy before saying the number that represents the dots shown to them. As shown in table 4, the children used three main strategies; subitizing, counting in ones and guessing. Subitizing is the ability to rapidly determine the quantity of a small array of objects without counting. Subitizing and counting in ones are two favourite strategies.

For both groups, the number of children who used the subitize strategy decreases when the numbers of dots increase (see Diagram 1 and Diagram 2). For example, 14 (93.3\%) children of year six used to subitize one dot to represent 1 and one child (6.7\%) subitize eight dots. For seven, nine and ten dots, none of the six-yearsold children subitized them. Interestingly, there were representatives of five-year-old children who subtized all 
dots. In this group $10(66.7 \%)$ of them subitized one dots and decrease to $1(6.7 \%)$ child for ten dots. Both groups tended to subitize the number less than seven the dots.

Next, the children of both ages used counting in one strategy for all dots. However, several patterns appear. First, all six-year-children who did not utilize subitizing strategy, chose counting in one as their favourite strategy. None of them guessed to represent the dots. One the same child $(n=1,6.7 \%)$ counted in one incorrectly. For five-yea- old children, apart from subitizing, counting in one became a popular strategy among them and only a maximum of $2(13.3 \%)$ guessed wrongly.

\begin{tabular}{|c|c|c|c|c|c|c|c|c|c|c|c|}
\hline \multirow[t]{2}{*}{$\begin{array}{l}\text { No. of } \\
\text { Dots }\end{array}$} & \multirow[b]{2}{*}{ Age } & \multicolumn{2}{|c|}{ Subitize } & \multicolumn{2}{|c|}{$\begin{array}{c}\text { count in ones / } \\
\text { correct }\end{array}$} & \multicolumn{2}{|c|}{$\begin{array}{l}\text { count in ones / } \\
\text { wrong }\end{array}$} & \multicolumn{2}{|c|}{ Guess/ wrong } & \multicolumn{2}{|c|}{ Don't know } \\
\hline & & $n$ & $\%$ & $n$ & $\%$ & $n$ & $\%$ & $n$ & $\%$ & $n$ & $\%$ \\
\hline \multirow{2}{*}{1} & 5 & 10 & 66.7 & 5 & 33.3 & 0 & 0.0 & 0 & 0.0 & 0 & 0.0 \\
\hline & 6 & 14 & 93.3 & 1 & 6.7 & 0 & 0 & 0 & 0 & 0 & 0 \\
\hline \multirow{2}{*}{2} & 5 & 6 & 40.0 & 8 & 53.3 & 0 & 0 & 1 & 6.7 & 0 & 0 \\
\hline & 6 & 8 & 53.3 & 7 & 46.7 & 0 & 0 & 0 & 0.0 & 0 & 0 \\
\hline \multirow{2}{*}{3} & 5 & 6 & 40.0 & 9 & 60.0 & 0 & 0 & 0 & 0.0 & 0 & 0 \\
\hline & 6 & 8 & 53.3 & 7 & 46.7 & 0 & 0 & 0 & 0.0 & 0 & 0 \\
\hline \multirow{2}{*}{4} & 5 & 4 & 26.7 & 7 & 46.7 & 3 & 20.0 & 1 & 6.7 & 0 & 0 \\
\hline & 6 & 9 & 60.0 & 6 & 40.0 & 0 & 0 & 0 & 0.0 & 0 & 0 \\
\hline \multirow{2}{*}{5} & 5 & 3 & 20.0 & 8 & 53.3 & 4 & 26.7 & 0 & 0.0 & 0 & 0 \\
\hline & 6 & 5 & 33.3 & 9 & 60.0 & 1 & 6.7 & 0 & 0.0 & 0 & 0 \\
\hline \multirow{2}{*}{6} & 5 & 1 & 6.7 & 11 & 73.3 & 3 & 20.0 & 0 & 0.0 & 0 & 0 \\
\hline & 6 & 1 & 6.7 & 14 & 93.3 & 0 & 0.0 & 0 & 0.0 & 0 & 0 \\
\hline \multirow{2}{*}{7} & 5 & 2 & 13.3 & 9 & 60.0 & 3 & 20.0 & 1 & 6.7 & 0 & 0 \\
\hline & 6 & 0 & 0.0 & 15 & 100.0 & 0 & 0.0 & 0 & 0.0 & 0 & 0 \\
\hline \multirow{2}{*}{8} & 5 & 0 & 0.0 & 10 & 66.7 & 2 & 13.3 & 1 & 6.7 & 2 & 13.3 \\
\hline & 6 & 1 & 6.7 & 10 & 66.7 & 4 & 26.7 & 0 & 0.0 & 0 & 0 \\
\hline \multirow{2}{*}{9} & 5 & 2 & 13.3 & 4 & 26.7 & 9 & 60.0 & 0 & 0.0 & 0 & 0 \\
\hline & 6 & 0 & 0.0 & 14 & 93.3 & 1 & 6.7 & 0 & 0.0 & 0 & 0 \\
\hline \multirow{2}{*}{10} & 5 & 1 & 6.7 & 6 & 40.0 & 6 & 40.0 & 2 & 13.3 & 0 & 0 \\
\hline & 6 & 0 & 0.0 & 14 & 93.3 & 1 & 6.7 & 0 & 0.0 & 0 & 0 \\
\hline
\end{tabular}

Table 4: The strategies used to say the numbers that represent the dots

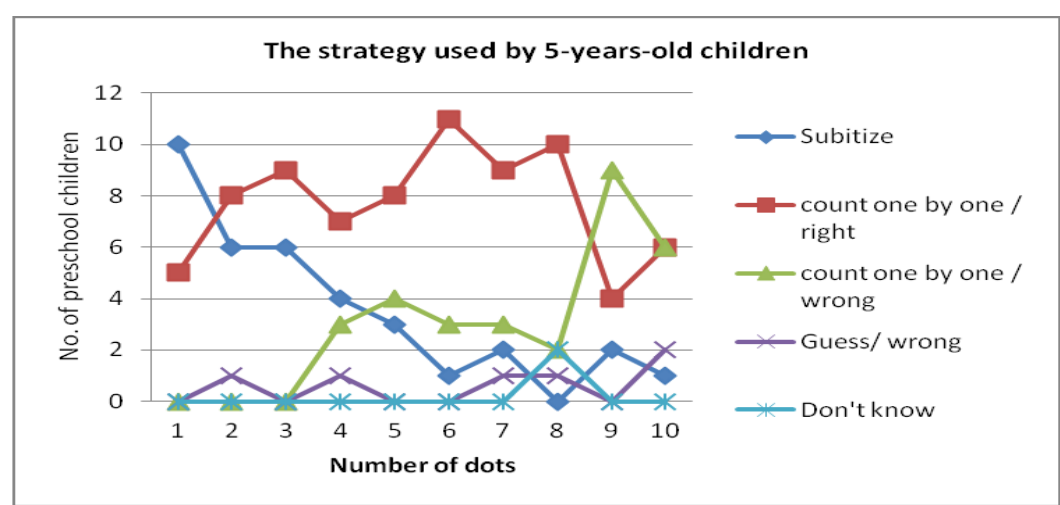

Diagram 1: The strategies used by 5 -years old children 


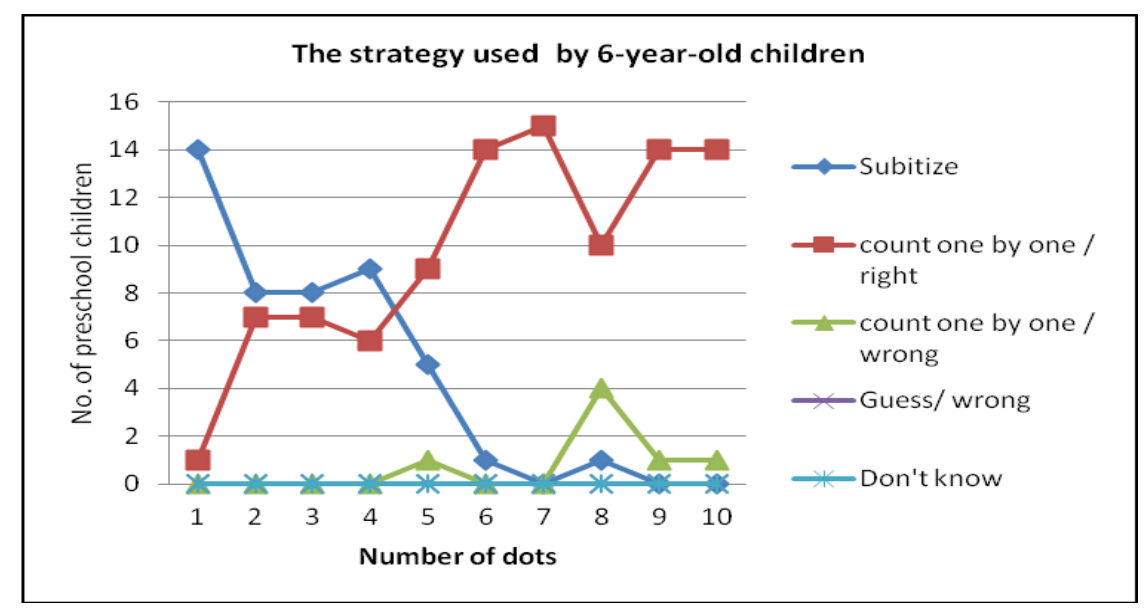

Diagram 2: The strategies used by 6-years-old children

Second, the number of children of both groups who used this strategy increases (including wrong and correct response) when the number of dots increases. For example, 5 (33.3\%) of five-year-old children counted in ones for one dot and $12(80 \%)$ for ten dots. Among six-year- old children, only $1(6.7 \%)$ child counted in one for one dot and the number increases to $15(100 \%)$ children for ten dots.

Third, the children of five-year-old used to count in one wrongly for four up to ten dots. The maximum number of five-year-old children who counted in ones wrongly was for nine dots $(\mathrm{n}=9,60)$ followed by ten dots $(n=6,40 \%)$, five dots $(n=4,26.7 \%)$, and four, six and seven dots $(n=3,20 \%)$ respectively. The wrongly used count in one strategy among six years old children happened for eights dots $(n=4,26.7 \%)$, and for five, nine and tens dots $(\mathrm{n}=1,6.7 \%)$ respectively.

\section{Discussion}

Saying the number names is one of the ways to represent numbers. The findings show that the older children did better than the younger. In general, the five-year-old children were good at saying lower numbers ( 1 to 5) and faced problems representing greater numbers (6 to 10) even though some were good. The children have the ability to represent the number (say the number name) and it occurs developmentally since the children take time to associate the symbols or numeral and number names. Thus, the inability to say the number names for greater numbers ( 6 to 10 ) is a temporary problem and can be solved by drilling and practice more frequently.

Using objects is another way to represent numbers. In the study, most of the children did not have the problem in saying the number and counting the fingers simultaneously except for three year-old-five children. Representing numbers using objects looks easier as compared to say the number names. The findings support the Piaget (1972) of Cognitive Developmental Theory where the children learn through the concrete operational stage. Representing number by saying the number names look more abstract.

Saying number to represent a number of objects is another form representation. Almost all six-year-old children were able to say the number correctly when groups of objects of small $(2,3$, and 4$)$ and big $(8,9$, and 10) quantities were displayed. Whereas, the five-year-old children were good at saying number names with respect to objects of small quantity only. The findings are consistent with the earlier representation (saying number names to represent numbers). Here the "complexity" of the object of big quantity places the greater challenge in saying the numbers.

The children require strategies to represent a group of objects correctly. In our study, subitizing (look and say rapidly) and counting in ones are two favorite strategies use to say the number related to number of dots given. Subitizing differs from guessing in the sense that during guessing the children are not really confident and take longer time to provide the answer. Children prefered to subitize for fewer number of dots and opted to count in ones for a larger numbers of dots (6 to 10). The findings support other results of the study (Piazza, Mechelli, Butterworth \& Price, 2002; Benoit, Lehalle \& Jouen,2004) study. However, more six-year-old children did better in subitizing compared to five-year-old children. Hence the results also agree with the view that "subitizing appears to be the developmental pathway for acquiring the meaning of the first few number words, since it allows the child to grasp the whole and the elements at the same time. Benoit, Lehalle \& Jouen, 2004, p291". The children's selection of counting in ones when they were not confident enough to subitize particularly for a greater quantity was also mentioned in other study. However, the use of counting in ones remains an effective strategy when the almost all six-year-old children manage to provide correct representations. 


\section{Conclusion}

Pre-school children are able to conceptualize numbers using multiple representations In the study the most of the children were able say the number names that represent the numerals (1-10). They were also manage to count the number of objects (fingers and marbles) to represent the numbers. In order to represent the number dots in numbers correctly the children employed three main strategies; subitizing, counting in ones and guessing. Subitizing and counting are effective strategies for pre school children. Multiple representation plays a vital roles in learning and it invites the children to utilize the strategy they are confortable with.

[1] Munirah, G. (2001). Kajian kepekaan nombor murid tahun lima. Unpublished Doctoral Thesis, Universiti Teknologi Malaysia, Johor Bahru.

[2] Parmjit, S. (2005, Aug. 7 - 12). Multiplicative thinking in children's learning at early grades. Paper presented at the ICMI East Asia regional Conference on Mathematics Education, China.

[3] Munirah, G., \& Noor Azlan, A. Z. (1999). Assessment of school children's number sense Proceedings of The International Conference on Mathematics Education into the 21 Century: Societal Challenges: Issues and approaches. Cairo, Egypt.

[4] Chinnapan, M., \& Pandian, A. (2009). Malaysian and Australian children's representations and explanations of numeracy problem. Educational Research for Policy and Practice 8(3), 197-209.

[5] Mohini, M., \& Jacinta, J. (2010). Investigating Number Sense Among Students. Procedia Social and Behavioral Sciences, 8, 317324.

[6] Lamon, S. J. (2001). Presenting and representing: From fractions to rational numbers. In A. Cuoco (Ed.), The role of representation in school mathematics. 2001 Yearbook of the National Council of Teachers of Mathematics (pp. 173-174). Reston, VA: National Council of Teachers of Mathematics

[7] Janvier, C. (1987). Representation and understanding: The notion of function as an example. In C. Janvier (Ed.), Problems of representation in the teaching and learning mathematics (pp. 67-72). Hillsdale, NJ: Lawrence Erlbaum Associates.

[8] Lesh, R., Post, T., \& Behr, M. (1987). Representations and translations among representations in mathematics learning and problem solving. In C. Janvier (Ed.), Problems of representations in the teaching and learning of mathematics (pp. 33-40). Hillsdale, NJ: Lawrence Erlbaum.

[9] Kaput, J. (1991). Notation and representations as mediator of constructive processes. In E. von Glasersfeld (Ed.), Radical constructivism in mathematics education (pp. 53-74). Hillsdale, NJ: Lawrence Erlbaum Associates.

[10] National Council of Teachers of Mathematics (2000). Principles and standards for school mathematics. Reston, VA: NCTM.

[11] Borko, H., \& Putnam, R. T. (1996). Learning to teach. In D. C. Berliner \& R. C. Calfe (Eds.), Handbook of Educational Psychology (pp. 673-708). New York: Simon \& Schuster MacMillan.

[12] Seeger, F., Voight, I., \& Werschescio, V. (1998). Representations in the mathematics classroom: reflections and constructions. In F. Seeger, I. Voight \& V. Werschescio (Eds.), The Culture of the Mathematics Classroom (pp. 308-343). Cambridge: Cambridge University Press.

[13] Cobb, P., Yackel, E., \& Wood, T. (1992). A constructivist alternative to the representational view of mind in mathematics education. Journal for Research in Mathematics Education, 23(1), 2-33.

[14] Goldin, G., \& Shteingold, N. (2001). Systems of representations and the development of mathematical concepts. In A. Cuoco \& F. Curcio (Eds.), The roles of representation in school mathematics. Reston, VA: National Council of Teachers of Mathematics.

[15] Pape, S. J., \& Tchoshanov, M. A. (2001). The role of representation(s) in developing mathematical understanding. heory into Practice, 40(2), 118-127.

[16] Goldin, G. A., \& Janvier, C. (1998). Representations and the psychology of mathematics education. Journal of Mathematical Behavior, 17(1), 1-4.

[17] Goldin, G. A. (1998a). Representational systems, learning, and problem solving in mathematics. Journal of Mathematical Behavior, 17(2), 137-165.

[18] Dienes, Z. P. (1960). Building up mathematics. London: Hutchinson.

[19] Bruner, J. S. (1966). Toward a theory of instruction. Cambridge Mass: Harvard University Press.

[20] Pirie, S., \& Kieren, T. (1994b). Growth in mathematical understanding: How can we characterize it and how can we represent it? Educational Studies in Mathematics, 26, 165-190.

[21] Owens, K. D., \& Clements, M. A. (1997). Representations in spatial problem solving in the classroom. Journal of Mathematical Behavior, $17(2), 197-218$.

[22] Suh, J., \& Moyer, P. S. (2007). Developing students' representational fluency using virtual and physical algebra balances. The Journal of Computers in Mathematics and Science Teaching, 26(2), 155-173.

[23] Lesh, R. (1979). Mathematical learning disabilities: considerations for identification, diagnosis and remediaton. In R. Lesh, D. Mierkiewicz \& M. G. Kantowski (Eds.), Applied Mathematical Problem Solving. Ohio: ERIC/SMEAC.

[24] Thomas, N. D., Mulligan, J. T., \& Goldin, G. A. (2002). Children's representation and structural development of the counting sequence 1-100. Journal of Mathematical Behavior, 21, 117-133.

[25] Ainsworth, S. E., \& van Labeke, N. (2002). Using a multi-representational design framework to develop and evaluate a dynamic simulation environment. Paper presented at the 10th European Conference for Research on Learning and Instruction.

[26] Piaget, J. (1972). The psychology of the child. New York: Basic Books.

[27] Piazza, M., Mechelli, A., Butterworth, B., \& Price, J. (2002). Are subitizing and counting implemented as separate or functionally overlappign process. Neurolmage, 15, 435-446.

[28] Benoit, L., Lehalle, H., \& Jouen, F. (2004). Do young children acquire number words through subitizing or counting. Cognitive Development, 19, 291-307. 
